\title{
Notes on the vocalizations of Short-tailed Antthrush (Chamaeza campanisona)
}

Peter Boesman

In the following we briefly analyze and compare voice of the different races of Short-tailed Antthrush (Chamaeza campanisona). We also try to quantify the extent of any vocal differences using the criteria proposed by Tobias et al. (2010), as a support for taxonomic review. We have made use of sound recordings available on-line from Xeno Canto (XC) and Macaulay Library (ML).

Song of all races is structurally similar, but with clear differences in a number of parameters (Fig. 1). Twelve races are currently recognized, but from a first comparison, it would seem that there are five vocal groups. We have taken measurements for a number of basic sound parameters of the loudsong:

Group 1: Northern Venezuelan mountains (venezuelana)

First part of song

$\begin{array}{ll}\text { \# notes } & 13-18 \\ \text { pace* at start } & 0.42-0.47 \\ \text { pace at end } & 0.25-0.275 \\ \text { max. mid freq. } & 930-1040 \mathrm{~Hz} \\ \text { max. note length } & 0.2-0.215 \mathrm{~s} \\ \text { d part of song } & \\ \text { \# notes } & 6-9 \\ \text { freq. drop } & 150-380 \mathrm{~Hz} \\ \text { note length } & 0.16-0.2 \mathrm{~s} \\ \text { pace } & 0.344-0.37 \\ \text { ength } & 7.25-8 \mathrm{~s}\end{array}$

Group 2: Tepuis of SE Venezuela (presumed obscura)

First part of song

$\begin{array}{ll}\text { \# notes } & >50, \text { barely countable at end } \\ \text { pace at start } & 0.34-0.47 \\ \text { pace at end } & 0.074-0.076 \\ \text { max. mid freq. } & 811-880 \mathrm{~Hz} \\ \text { max. note length } & 0.16-0.2 \mathrm{~s} \\ \text { d part of song } & \\ \text { \# notes } & 4-7 \\ \text { freq. drop } & 140-220 \mathrm{~Hz} \\ \text { note length } & 0.14-0.16 \mathrm{~s} \\ \text { pace } & 0.35-0.37 \\ \text { ength } & 9.3-10.3 \mathrm{~s}\end{array}$

Total length

$9.3-10.3 s$

* pace: measured here as period, duration between 2 subsequent notes in seconds. 
Group 3: Andes from Colombia to N Peru

First part of song

$\begin{array}{ll}\text { \# notes } & 21-29 \\ \text { pace at start } & 0.30-0.36 \\ \text { pace at end } & 0.18-0.20 \\ \text { max. mid freq. } & 1050-1120 \mathrm{~Hz} \\ \text { max. note length } & 0.13-0.15 \mathrm{~s}\end{array}$

Second part of song

\# notes

8-12

freq. drop

350-480hz

note length

$0.14-0.18 \mathrm{~s}$

pace

0.34-0.39

Total length

9.0-11.0s

Group 4: Andes from C Peru to Bolivia First part of song

$\begin{array}{ll}\text { \# notes } & 48->60 \\ \text { pace at start } & 0.15-0.16 \\ \text { pace at end } & 0.09-0.12 \\ \text { max. mid freq. } & 1100-1180 \mathrm{~Hz} \\ \text { max. note length } & 0.10-0.11 \mathrm{~s}\end{array}$

Second part of song

\# notes

11-22

freq. drop $\quad 400-420 \mathrm{~Hz}$

note length $\quad 0.09-0.14 \mathrm{~s}$

pace $\quad 0.17-0.22$

Total length $\quad 9.84-11.65 \mathrm{~s}$

Group 5: Atlantic Brazil

$\begin{array}{ll}\text { First part of song } & \\ \text { \# notes } & 52->80 \\ \text { pace at start } & 0.155-0.21 \\ \text { pace at end } & 0.12-0.15 \\ \text { max. mid freq. } & 1060-1140 \mathrm{~Hz} \\ \text { max. note length } & 0.095-0.12 \mathrm{~s} \\ \text { Second part of song } & \\ \text { \# notes } & 3-11 \text { (usually just a few, occasionally more) } \\ \text { freq. drop } & 180-400 \mathrm{~Hz} \\ \text { note length } & 0.05-0.08 \mathrm{~s} \\ \text { pace } & 0.12-0.17 \\ \text { Total length } & 8.3-14.5 \mathrm{~s}\end{array}$

Discussion:

Group 1: Northern Venezuelan mountains (venezuelana) stands apart in many aspects: lowest number of notes, slowest pace at start, slowest pace at end, longest notes and shortest song (even compared to N Andes group)! 


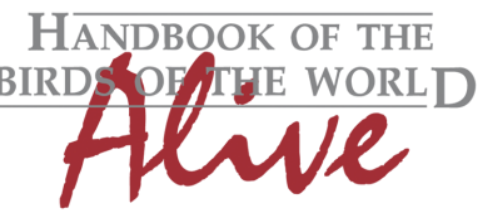

\section{ORNITHOLOGICAL NOTES}

Group 2 is unique in having an extreme acceleration (ratio 'pace at start/pace at end') (score 3-4) and having the lowest frequency (score about 2 if more samples confirm this)

Group 3, while less so than group 1, differs from group 4 and 5 in its lower number of notes, slower pace at start and end, and equally so in the second part of the song.

Group 4 and 5 are quite similar, but can still be safely separated by the second part of the song, which is quite different: group 4 has more notes which are longer and delivered at a slower pace (total score approx. 3).

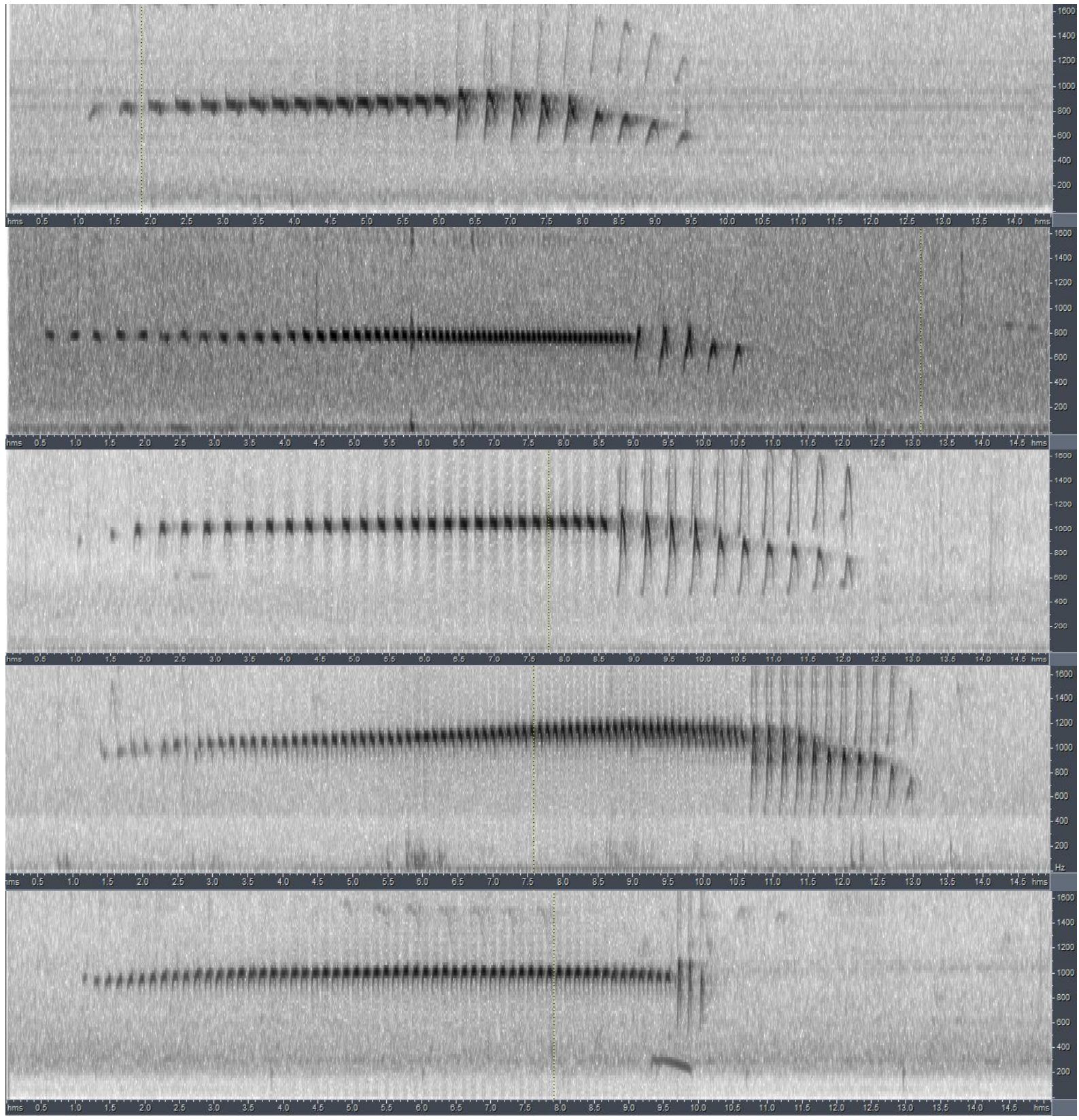

Figure 1: from top to bottom: Group 1, 2, 3, 4 and 5. 

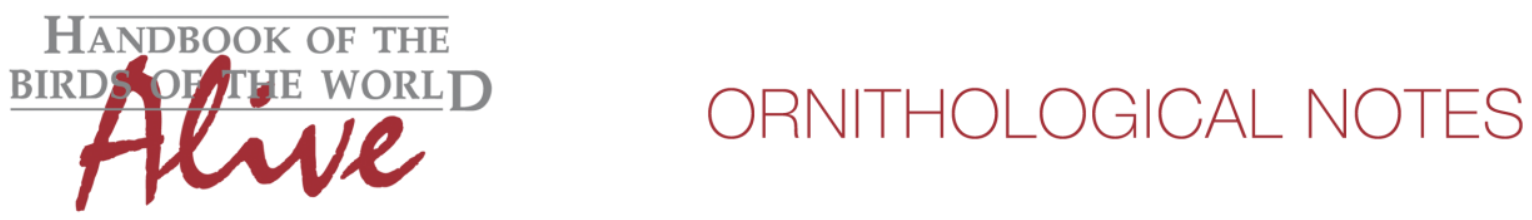

If a 5-way separation in groups or species can't be supported by other characters, then clustering group 1 and 3 , and group 4 and 5 would result in 3 groups with still clearly defined vocal differences:

First part of song

$\begin{array}{lll}\text { \# notes } & 13-29 & 48->80 \\ \text { pace at start } & 0.30-0.47 & 0.15-0.21 \\ \text { pace at end } & 0.18-0.275 & 0.09-0.15 \\ \text { max. note length } & 0.13-0.215 \mathrm{~s} & 0.095-0.12 \mathrm{~s} \\ \begin{array}{ll}\text { d part of song } \\ \text { note length }\end{array} & 0.16-0.2 \mathrm{~s} & 0.05-0.14 \mathrm{~s} \\ \text { pace } & 0.344-0.39 & 0.12-0.22\end{array}$

The clustering of group 4 and 5 seems however somewhat counter-intuitive based on distribution.

This note was finalized on 12th June 2015, using sound recordings available on-line at that moment. We would like to thank in particular the many sound recordists who placed their recordings for this species on XC and ML.

\section{References}

Tobias, J.A., Seddon, N., Spottiswoode, C.N., Pilgrim, J.D., Fishpool, L.D.C. \& Collar, N.J. (2010). Quantitative criteria for species delimitation. Ibis 152(4): 724-746.

\section{Recommended citation}

Boesman, P. (2016). Notes on the vocalizations of Short-tailed Antthrush (Chamaeza campanisona). HBW Alive Ornithological Note 75. In: Handbook of the Birds of the World Alive. Lynx Edicions, Barcelona. (retrieved from http://www.hbw.com/node/931963 on 18 May 2016). 